practice compared to patients included in controlled trials. Our results also suggest that there is a clear need for a steroid sparing agent in patients with GCA, that is a older aged population prone to CS side effects.

Disclosure of Interest: None declared

DOI: 10.1136/annrheumdis-2018-eular.3983

\section{SAT0527 RITUXIMAB PRESCRIPTION PATTERNS AND EFFICACY IN THE INDUCTION TREATMENT OF ANCA- ASSOCIATED VASCULITIS IN A BELGIAN MULTICENTRIC COHORT}

F. Vandergheynst ${ }^{1}$, P. Chasseur ${ }^{1}$, J.-B. Nicolas ${ }^{2}$, C. von Frenckell ${ }^{3}$, D. Blockmans ${ }^{4} .{ }^{1}$ Internal Medicine, Erasme Hospital, Brussels; ${ }^{2}$ Internal Medicine, CHU Mont-Godinne, Yvoir, ${ }^{3}$ Rheumatology, CHU Sart-Tilman, Liège; ${ }^{4}$ Internal Medicine, UZ Gasthuisberg, Leuven, Belgium

Background: The RAVE trial has revolutionised the induction treatment of ANCA-Associated Vasculitis (AAV, including GPA, granulomatosis with polyangiitis and MPA, microscopic polyangiitis), by demonstrating non-inferiority of rituximab compared with cyclophosphamide ${ }^{1}$.

Objectives: To study AAV patients' characteristics, rituximab prescription practices and efficacy in AAV induction treatment in 4 Belgian university hospitals. The patient population, selected according to the Belgian reimbursement criteria, is relatively homogeneous and comparable to the one of RAVE trial.

Methods: 57 patients, receiving rituximab as AAV induction therapy since May 2014, were enrolled in an observational retrospective multicenter trial involving 4 Belgian university hospitals. We have focused on the type of AAV (GPA/MPA), ANCA specificity (anti-PR3/MPO), prescriber's speciality, used reimbursement criteria, organ involvements, severity of the flares (according to BVAS-WG definition) and finally rituximab efficacy in AAV induction treatment by considering the RAVE primary (complete remission without prednisone) and secondary (complete remission with prednisone $<10 \mathrm{mg}$, rates of relapses) outcomes at $6,12,18$ and 24 months.

Results: The most frequent subtype of AAV was GPA (84\%). The main indication was relapsing disease $(54.4 \%)$, followed by contra-indication to cyclophosphamide $(38.6 \%)$. $66.7 \%$ of the patients reached complete remission with prednisone $<10 \mathrm{mg}$ at 6 months, and $55.3 \%$ at 12 months, $40 \%$ at 18 months, $25 \%$ at 24 months respectively. In the "severe disease" subgroup, $73 \%$ reached complete remission with prednisone $<10 \mathrm{mg}$ at 6 months, $58.8 \%$ at 12 months, $50 \%$ at 18 months and $32 \%$ at 24 months. The rates of complete remission without steroids were very low at $6,12,18$ and 24 months (between $0 \%-6 \%$ ) but our patients were not asked to follow a glucocorticoid tapering scheduled for complete withdrawal of prednisone after 6 months and were usually maintained under lowdose prednisone. Relapse rates were high between 18 and 24 months both in the total group and in the severe disease subgroup (due to the fact that rituximab is not reimbursed for maintenance treatment in Belgium). The subtype of ANCA was not predictive of the risk of relapse.

Conclusions: Our results confirm - in a "real-life" cohort of patients selected according data of RAVE trial - those of RAVE regarding complete remission rates at 6 months with prednisone $10 \mathrm{mg} / \mathrm{j}$. The high prevalence of relapses - in particular after 18 months - underlines the need to optimise maintenance treatment after an induction treatment with rituximab.

\section{REFERENCE:}

[1] Specks U, Merkel PA, Seo P, et al. Efficacy of remission-induction regimens for ANCA-associated vasculitis. N Engl J Med 2013:369(5):417-27.

Disclosure of Interest: None declared DOI: 10.1136/annrheumdis-2018-eular.1881

\section{SAT0528 \\ EFFECTIVENESS OF REMISSION-INDUCTION THERAPY WITH CONCOMITANT CYCLOPHOSPHAMIDE AND GLUCOCORTICOID FOR MICROSCOPIC POLYANGIITIS AND GRANULOMATOSIS WITH POLYANGIITIS IN JAPAN: A PROPENSITY SCORE MATCHED ANALYSIS OF TWO NATIONWIDE PROSPECTIVE COHORT STUDIES}

H. Watanabe ${ }^{1}$, K.-E. Sada ${ }^{1}$, Y. Matsumoto ${ }^{1}$, M. Harigai ${ }^{2,3}$, H. Makino ${ }^{4}$ on behalf of Japan Research Committee of the Ministry of Health, Labour, and Welfare for Intractable Vasculitis (JPVAS). ${ }^{1}$ Department of Nephrology, Rheumatology,

Endocrinology and Metabolism, Okayama University Graduate School of Medicine, Dentistry and Pharmaceutical Sciences, Okayama; ${ }^{2}$ Department of Pharmacovigilance, Graduate School of Medical and Dental Sciences, Tokyo Medical and Dental University; ${ }^{3}$ Division of Epidemiology and Pharmacoepidemiology of Rheumatic Diseases, Institute of Rheumatology, Tokyo Women's Medical University, Tokyo; ${ }^{4}$ Okayama university, Okayama, Japan

Background: Although concomitant use of cyclophosphamide (CYC) with glucocorticoids (GC) is considered to be one of the standard remission-induction therapies for antineutrophil cytoplasmic antibody (ANCA) associated vasculitis over 30 years, there are few reports about clinical efficacy or effectiveness of CYC.

Objectives: To evaluate effectiveness and safety of concomitant CYC as remis sion induction therapy in Japanese patients with microscopic polyangiitis (MPA) and granulomatosis with polyangiitis (GPA) using data sets from two nationwide prospective cohort studies.

Methods: Newly diagnosed MPA and GPA patients treated with GC with or without $C Y C$ for remission-induction therapy were enrolled. The patients treated with other immunosuppressants or plasma exchange were excluded. A propensity score for the use of CYC was estimated using age, types of AAV, serum creatinine level, Birmingham Vasculitis Activity Score (BVAS), and initial GC dosage a baseline. After propensity score matching at 1:1, remission, overall survival, and end-stage renal disease (ESRD)-free survival rates, Vasculitis Damage Index (VDI), and incidence of serious infection within 6 months were compared between patients treated with and without concomitant CYC.

Results: Of enrolled 327 patients, concomitant CYC was used in $119(36 \%)$ patients during the initial 3 weeks of treatment. After propensity score matching, 95 patients with concomitant CYC (CYC group) and 95 controls (non-CYC group) were selected. Demographics, baseline characteristics and treatments were balanced between the two groups except for myeloperoxidase ANCA positivity (Table). The remission within 6 months was achieved in $85 \%$ in both groups. The survival and ESRD-free survival rates were also similar between the two groups (log-rank test; $p=0.77$ and 1.0, respectively). Median VDI at the time of last observation did not differ between the two groups (CYC, 3 [interquartile $\{I Q R\}: 2-4$ ] non-CYC, 2 [IQR:1-3], $p=0.26$ ). The accumulated GC dosage of the CYC-group from 3 to 24 months was lower than the non-CYC group, the GC-related damage did not differ (CYC, 1 [IQR: 0-2]; non-CYC, 0 [IQR:0-2], p=0.69).

Table. Comparison of patients treated with concomitant cyclophosphamide and with glucocorticoid alone

\begin{tabular}{|c|c|c|c|}
\hline Variables at baseline and treatments & $\begin{array}{l}\text { Cyclophosphamide users } \\
\qquad(\mathrm{n}=95)\end{array}$ & $\begin{array}{c}\text { Non-users } \\
(n=95)\end{array}$ & $p$-value \\
\hline Male/female, $n$ & $51 / 44(46 \%)$ & $60 / 35$ & 0.24 \\
\hline Age, years & $70(65-78)$ & $71(62-75)$ & 0.92 \\
\hline GPA/MPA & $26 / 69$ & $27 / 68$ & 1.0 \\
\hline Myeloperoxidase ANCA, $n$ (\%) & $78(82)$ & $89(94)$ & $0.02^{*}$ \\
\hline Proteinase-3 ANCA, n (\%) & $17(18)$ & $8(8)$ & 0.15 \\
\hline Serum creatinine, $\mathrm{mg} / \mathrm{dL}$ & $1.2(0.8-3.2)$ & $1.1(0.7-2.5)$ & 0.39 \\
\hline C-reactive protein, $\mathrm{mg} / \mathrm{dL}$ & $7.5(2.3-12.6)$ & $7.2(2.1-11.7)$ & 0.35 \\
\hline BVAS & $15(12-20)$ & $16(12-21)$ & 0.99 \\
\hline Interstitial lung disease, $\mathrm{n}(\%)$ & $38(40)$ & $37(49)$ & 0.55 \\
\hline Glucocorticoid (mg/kg/day) ${ }^{d}$ & $0.83(0.72-0.97)$ & $0.83(0.67-0.99)$ & 0.89 \\
\hline
\end{tabular}

Values expressed as a number of patients (\%) or median (interquartile). ${ }^{*} \mathrm{p}<0.05$.

Conclusions: In Japanese patients with MPA and GPA, concomitant CYC could not show any benefits on clinical outcomes within 24 months. Dosage and treatment duration of CYC, as well as tapering methods of GC, could be confounding factors. Longer observation may be necessary to confirm the effectiveness of CYC as GC sparing agent.

Disclosure of Interest: None declared

DOI: 10.1136/annrheumdis-2018-eular.1689 